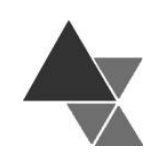

\title{
Fatores associados à adesão e à descontinuidade ao programa "Cestas Verdes”, vertente do Programa de Aquisição de Alimentos (PAA) em Limeira, SP.
}

\author{
Mariana Fagundes Griloº , Bárbara Lellis de Sá Frizo² e Julicristie Machado de Oliveira ${ }^{3}$
}

Com o intuito de assegurar o Direito Humano à Alimentação Adequada (DHAA), o governo federal brasileiro instituiu o Programa de Aquisição de Alimentos (PAA). Em Limeira, SP, a política teve uma gestão específica com o programa "Cestas Verdes", que fornecia alimentos produzidos localmente a famílias em risco social. O presente estudo teve como objetivo investigar os fatores associados à adesão e descontinuidade dos beneficiários, diagnosticar prevalência de (In)Segurança Alimentar e Nutricional (IAN/SAN), e entender o papel do programa em assegurar o DHAA. Para isso, 68 beneficiários responderam um questionário com dimensões de IAN/SAN e informações específicas do programa, como motivos que condicionaram a adesão e descontinuidade e impacto dos alimentos nos hábitos alimentares. Os dados foram analisados com o auxílio do software EpiData. Entre os domićlios beneficiados, 94,1\% encontravam-se classificados em algum grau de IAN. Mais de 95\% dos beneficiários referiram que os alimentos recebidos tornavam a alimentação mais saudável, evidenciando impactos nos hábitos alimentares. Quanto à frequência de recebimento, $64 \%$ não receberam a cesta durante toda a vigência do programa, o que foi explicado por fatores de âmbito individual dos beneficiários - condições de saúde - e da gestão da política - cadastramento tardio, horário de entrega, viés e mudança nos critérios de seleção. Assim, as "Cestas Verdes" mostraram-se como contribuidoras na garantia do DHAA de populações em risco social. Em relação à descontinuidade, essa se deu por fatores relacionados tanto às condições de vida dos beneficiários quanto às características da gestão municipal.

Palavras-chave: Programas e Políticas de Nutrição e Alimentação, Direitos Humanos, Segurança Alimentar e Nutricional.

${ }^{1}$ Graduada em Nutrição pela Faculdade de Ciências Aplicadas - Universidade Estadual de Campinas. Endereço para correspondência: Rua Francisco Leoni no 46, Jardim Teresa, Itatiba, SP. Tel.: (11)975660068. E-mail: marianafgrilo@gmail.com

${ }^{2}$ Mestra em Ciências Humanas e Sociais Aplicadas pelo Programa Interdisciplinar em Ciências Humanas e Sociais Aplicadas pela Faculdade de Ciências Aplicadas - Universidade Estadual de Campinas.

${ }^{3}$ Doutora em Nutrição em Saúde Pública pela Faculdade de Saúde Pública - Universidade de São Paulo. Docente do Curso de Graduação em Nutrição e do Mestrado Interdisciplinar em Ciências Humanas e Sociais Aplicadas pela Faculdade de Ciências Aplicadas - Universidade Estadual de Campinas. 


\section{Factors associated with adhesion and discontinuity to the "Food Basket" program, part of the Food Acquisition Program (PAA) in Limeira, SP.}

In order to ensure the Human Right to Food (HRF), the Brazilian federal government instituted the Food Acquisition Program (PAA). In Limeira, SP, the policy had a specific management, with the "Food Basket" program, which provided food produced locally to families in social risk. The present study had as objective to investigate the factors associated with the adhesion and discontinuity of the beneficiaries, besides to diagnose the prevalence of Food and Nutrition (In)security (FNI/FNS) and to understand the role of the program in the HRF. To that end, 68 beneficiaries answered a questionnaire with FNI/FNS dimensions and specific information about the program, such as time of participation, reasons that conditioned adherence and discontinuity, and food impact in eating habits. The data were analyzed using the EpiData software. Among the beneficiarie's households, $94.1 \%$ were classified in some degree of FNS. More than $95 \%$ reported that the food received made eating healthier, evidencing impacts on eating habits. Regarding the frequency, 64\% did not receive the baskets during the whole program period. Discontinuity may be associated with individual factors of the enrolled beneficiary - health conditions - and policy management - late enrollment, delivery time, bias and change in selection criteria. Thus, the "Food Basket" program proved to be a contributor to the guarantee of the HRF of populations at social risk. Regarding the discontinuity, this was due to factors related to both the living conditions of the beneficiaries and the characteristics of municipal management.

Keywords: Nutrition Programs and Policies, Human Rights, Food and Nutrition Security.

\section{INTRODUÇÃO E OBJETIVOS}

A alimentação em quantidade e qualidade apropriadas é um direito humano básico assegurado pelo artigo 25 da Declaração Universal dos Direitos Humanos de 1948[1]. O Brasil, considerado um país com alto potencial agrícola e industrial na América Latina, tem grande parte de suas terras utilizadas para a produção de commodities alimentares[2]. No entanto, apesar de algumas interpretações serem positivas em relação ao desenvolvimento brasileiro, ainda persiste uma realidade de pobreza não superada, que também se expressa na fome e na Insegurança Alimentar e Nutricional (IAN), mesmo com as recentes tentativas de melhorias na distribuição de renda ${ }^{[3]}$.

O estado de IAN é resultado de diversos fatores, entre eles a disponibilidade de alimentos e a situação socioeconômica. No caso do Brasil, apesar da base econômica se sustentar no uso de terras para fins agropecuários, muitos de seus grupos populacionais não têm acesso à alimentação em quantidade e qualidade. Em 2013, verificou-se que 22,6\% dos domicílios brasileiros se encontravam em algum grau de IAN[4]. Como relatado por Josué de Castro[5], as fomes coletivas têm como um de seus principais fatores explicativos a falta de alimentos, que está diretamente ligada ao nível de renda[6].

Segundo a Pesquisa Nacional por Amostra de Domicílios (PNAD), mesmo em populações de baixa renda, o aumento do poder aquisitivo diminui a chance de ocorrência de IAN[7]. Assim, para promover a Segurança Alimentar e Nutricional (SAN), se faz necessário acabar com a pobreza, remetendo à responsabilidade do Estado de garantir alimentação adequada e saúde à população[8].

O país apresenta um relevante quadro teórico para SAN incluindo políticas públicas que são frutos de um prolongado processo de manifestações sociais e governamentais. Os programas públicos no Brasil adquiriram força no século $\mathrm{XX}$ e vem sendo aprimorados com o passar do tempo. Exemplos de iniciativas estratégicas são o Programa Fome Zero e a Política Nacional de Segurança Alimentar e Nutricional[?]. 
As intervenções brasileiras de SAN tem como objetivo combater, além da fome, as causas implícitas do problema, como a pobreza e a desigualdade, por meio de reformas estruturais e ações multissetoriais imediatas, que melhorem a situação socioeconômica e forneçam possibilidades de inclusão no meio de trabalho[10]. Essas atividades administradas pelos órgãos governamentais são compostas por programas de diferentes áreas e instituições do governo, como saúde, educação, assistência social, e desenvolvimento rural[9].

Instituído em 2003, o Programa de Aquisição de Alimentos (PAA) é uma das ações do Fome Zero e baseia-se na construção de uma proposta de SAN para o Brasil por meio do estímulo à produção e consumo da agricultura familiar, ao reconhecer a importância da comunicação entre políticas de fomento e de abastecimento alimentar. Além de valorizar a biodiversidade e a produção agroecológica, contribuir para a redução da emissão de gases do efeito estufa e estimular hábitos alimentares saudáveis ao escoar alimentos produzidos localmente ${ }^{[11,2]}$.

O programa contribui na luta contra a pobreza ao universalizar os direitos básicos por meio da criação de uma rede de proteção social às populações vulneráveis e garante, assim, por intermédio da alimentação, o fundamento para consolidação de padrões de qualidade de vida[13].

O Brasil retrata um cenário de transição nutricional comum aos países emergentes com mudanças no estilo de vida, incluindo o sedentarismo e as alterações no padrão alimentar, que é representado pelo reduzido consumo de frutas e hortaliças e a alta ingestão de produtos ultraprocessados, conhecidos por altos teores de gordura, açúcar e sal. Esses estão entre os principais fatores de risco para obesidade, agravo nutricional associado a incidência de doenças crônicas não transmissíveis, como diabetes e doenças cardiovasculares ${ }^{[14]}$.

Assim, o programa "Cestas Verdes", por meio da distribuição de cestas de alimentos in natura ricos em vitaminas, minerais e fibras, se expressa como uma estratégia de saúde coletiva ao viabilizar o acesso a alimentos de qualidade e culturalmente apropriados para populações em situação de vulnerabilidade. $\mathrm{O}$ objetivo deste estudo foi de investigar os fatores associados à adesão ou descontinuidade das famílias ao programa, permitindo uma avaliação do PAA em Limeira, SP, e seu possível impacto no DHAA e nos hábitos alimentares dos beneficiários do programa.

\section{MATERIAL E MÉTODOS}

O município de Limeira, localizado na porção centro-leste do estado de São Paulo (SP), é um dos municípios que participou do PAA. Com uma área de $580,71 \mathrm{~km}^{2}$ e população de 300.911 habitantes em 2017[15], o índice de pobreza no município é de $15,75^{[16]}$. Distribuídos pelas áreas de maior vulnerabilidade e risco social, existem os Centros de Referência de Assistência Social (CRAS), que são encarregados de proteger e diminuir situações de risco das populações consideradas socialmente vulneráveis, por meio do fortalecimento de vínculo entre as famílias e a comunidade ${ }^{[17]}$.

É mediante a parceria entre a Secretaria de Desenvolvimento Rural e do Meio Ambiente com o Centro de Promoção Social Municipal (CEPROSOM) que o PAA atuou em Limeira, SP. Os alimentos produzidos pela agricultura familiar no Acampamento Rural Elizabeth Teixeira, situado no Horto Florestal Tatu, Limeira, SP, eram comprados pelo programa com isenção de licitação e repassados ao CEPROSOM. Cestas compostas por frutas, hortaliças, raízes e tubérculos que variavam de acordo com a produção nas diferentes estações do ano eram montadas, constituindo o programa "Cestas Verdes". Essas cestas eram, então, distribuídas aos CRAS, que as concediam às famílias cadastradas na rede socioassistencial[17].

Para realização desse estudo descritivo, realizou-se o mapeamento dos beneficiários cadastrados para receber as "Cestas Verdes" em dois centros comunitários de Limeira, SP: Centro Comunitário Morro Branco, referenciado ao CRAS Nossa Senhora das Dores, e Centro Comunitário Odécio Degan, referenciado ao CRAS Casa das Famílias. Verificou-se que 21 e 47 beneficiários foram assistidos nos dois centros, respectivamente, durante 2015 e 2016. A distribuição das cestas sucedia-se de forma quinzenal ou mensal. Assim, a amostra estudada foi composta por 68 beneficiários que foram elegidos pelas assistentes sociais, de 
acordo com critérios de vulnerabilidade social do serviço, para serem incluídos no programa.

A equipe de pesquisadores acompanhou a rotina dos centros comunitários e entrevistou os beneficiários enquanto eles frequentavam o centro. Em alguns casos, as entrevistas foram realizadas nos domicílios. Utilizou-se um questionário composto por perguntas abertas e fechadas, dividido em duas partes. $\mathrm{Na}$ primeira parte, foram coletadas informações de identificação do beneficiário, composição familiar e questões de SAN domiciliar, além de questões sobre participação em outros programas como Bolsa Família, recebimento de cesta básica e de frequência alimentar habitual.

Para diagnosticar a prevalência de SAN/IAN, incluiu-se a Escala Brasileira de Insegurança Alimentar (EBIA), constituída por 14 questões sobre a condição alimentar do domićlio nos 90 dias anteriores à entrevista. Por meio dessa escala, é possível classificar o domicílio em 4 situações alimentares: i) Segurança alimentar (SA), ii) Insegurança alimentar leve (IA leve), iii) Insegurança alimentar moderada (IA moderada), e ix) Insegurança alimentar grave (IA grave) (4).

A SAN é caracterizada como a situação em que a família tem "acesso regular e permanente a alimentos de qualidade e em quantidade suficiente, e sequer se sentiam na iminência de sofrer restrição no futuro próximo". Na IA leve há a "preocupação ou incerteza quanto a disponibilidade de alimentos no futuro em quantidade e qualidade adequadas". $\mathrm{Na}$ IA moderada, por sua vez, há a "redução quantitativa de alimentos e/ou ruptura nos padrões de alimentação resultante da falta de alimentos entre os adultos". Por último, a condição de IA grave condiz à "redução quantitativa de alimentos e/ou ruptura nos padrões de alimentação resultante da falta de alimentos entre adultos e/ou crianças; e/ou privação de alimentos; fome" ${ }^{[4]}$.

$\mathrm{Na}$ segunda parte do questionário, foram registradas informações específicas sobre as "Cestas Verdes" com a finalidade de entender os fatores que condicionaram a permanência ou não no programa: se houve manutenção da adesão ou descontinuidade durante os dois anos de vigência do programa e quais motivos que as condicionaram.
Investigou-se as formas como os alimentos recebidos eram normalmente preparados e consumidos, além do grau de satisfação com o recebimento das cestas, se houve impacto dos alimentos obtidos nos hábitos alimentares das famílias. As questões foram formuladas com o intuito de investigar o papel do programa na garantia do DHAA. Registraram-se possíveis críticas e problemas vivenciados durante a permanência no programa.

Vale ressaltar que as entrevistas, aplicadas em 2017, foram realizadas após o encerramento do programa "Cestas Verdes", que teve vigência entre os anos de 2015 e 2016. Assim, a frequência de consumo alimentar relatada pelos beneficiários, bem como a situação de SAN/IAN, refere-se aos hábitos alimentares sem as contribuições das cestas. Quanto aos relatos de satisfação em relação aos alimentos recebidos, esses se referem à época em que o programa estava vigente.

\section{Aspectos Éticos}

O projeto de pesquisa foi aprovado pelo Comitê de Ética da PRP/Unicamp. Todos os princípios éticos foram respeitados na condução da pesquisa e todos os beneficiários foram esclarecidos em relação aos seus objetivos, receberam todas as informações solicitadas e puderam ou não consentir em participar mediante leitura e assinatura do Termo de Consentimento Livre e Esclarecido (TCLE). Os beneficiários dispunham do direito de retirar o consentimento a qualquer momento e seus direitos de privacidade foram assegurados.

\section{Banco e Análise de Dados}

Os dados quantitativos foram registrados, em duplicata, em banco elaborado no software EpiData. Os bancos foram checados em sua consistência, por meio de recurso disponível no software. Posteriormente, realizou-se as correções necessárias. O banco foi, então, importado para EpiData Analysis, para a realização de análise descritiva. Os beneficiários foram divididos em dois grupos, tomando como base a adesão ou a descontinuidade ao programa. Beneficiários que receberam cestas durante toda a duração do programa foram classificados como "adesão" e os que não receberam foram classificados como 
"descontinuidade". Em relação aos dados qualitativos, os mesmos foram transcritos em tabelas, agrupados de acordo com a pergunta que fora realizada. As respostas foram analisadas e organizadas em categorias para que as interpretações fossem realizadas em profundidade.

\section{RESULTADOS E DISCUSSÃO}

O PAA foi criado em 2003 como parte do Fome Zero, tendo sua implementação no município de Limeira, SP, em 2015, com a operacionalização particular de fornecer às famílias em situação de vulnerabilidade social cestas de produtos in natura produzidos pelo Acampamento Elizabeth Teixeira, consolidando o programa "Cestas Verdes". O programa, de caráter emergencial em que eram comprados alimentos de agricultores locais como forma de estímulo e fortalecimento a economia local, teve vigência de dois anos no município. Programas, vertentes do PAA, com características semelhantes ao "Cestas Verdes" também foram implementados em outras localidades, como Sorocaba, SP, e São Luís, MA[18,19].

O presente estudo teve como foco os beneficiários do programa "Cestas Verdes" no município de Limeira, SP. Resultados sobre os impactos da política pública sobre os agricultores participantes em Limeira, SP, podem ser encontrados em outro estudo[20].

Para isso, entrevistou-se 68 beneficiários do programa, 21 do Centro Comunitário Morro Branco e 47 do Centro Comunitário Odécio Degan. Primeiramente, caracterizou-se os indivíduos e seus domićlios. Como mostra a Tabela 1, a maioria dos beneficiários assistidos, além de se encontrarem em situação de vulnerabilidade econômica - critério decisivo para o cadastro no programa -, eram mulheres $(79,4 \%)$ e estavam na faixa etária acima de 60 anos $(39,7 \%)$. Essa cobertura de idade também foi observada como maioria entre indivíduos beneficiários do programa Restaurantes Populares, outra estratégia de promoção da garantia do DHAA, em todo o Brasil[21].
Tabela 1. Caracterização dos beneficiários e domicílios do programa "Cestas Verdes". 2017, Limeira, SP

\begin{tabular}{|c|c|c|}
\hline & $\mathrm{N}$ & $\%$ \\
\hline \multicolumn{3}{|l|}{ Sexo } \\
\hline Feminino & 54 & 79,4 \\
\hline Masculino & 14 & 20,6 \\
\hline \multicolumn{3}{|l|}{ Idade } \\
\hline $24-29$ & 3 & 4,4 \\
\hline $30-39$ & 12 & 17,7 \\
\hline $40-49$ & 13 & 19,1 \\
\hline $50-59$ & 13 & 19,1 \\
\hline $60-69$ & 20 & 29,4 \\
\hline $70-83$ & 7 & 10,3 \\
\hline \multicolumn{3}{|l|}{ Domicílio } \\
\hline Alugado & 22 & 32,4 \\
\hline Próprio/Cedido & 46 & 67,6 \\
\hline Participação em Programa & & \\
\hline \multicolumn{3}{|l|}{ Transferência de Renda } \\
\hline $\operatorname{Sim}$ & 23 & 33,8 \\
\hline Não & 45 & 66,2 \\
\hline
\end{tabular}

Do total de beneficiários, $77,9 \%$ relataram possuir alguma doença ou agravo à saúde. As mais predominantes foram obesidade, diabetes, hipertensão e doenças cardiovasculares. Em relação a participação em outros programas, 33,8\% participava de algum programa de transferência de renda. Entre eles, destacam-se Bolsa Família, Renda Cidadã e Benefício Assistencial ao Idoso e à Pessoa com Deficiência.

De acordo com análises de variadas políticas públicas de alimentação, verificou-se que o recebimento de alguma ajuda é uma estratégia determinante na garantia da subsistência de domicílios em situação de vulnerabilidade social e IAN, o que impacta nos hábitos alimentares dos moradores de domicílios que vivenciam condições de privação[22,23].

Além disso, todos os programas, incluindo os de transferência de renda, como o Bolsa Família; os de abastecimento de alimentos; e os do projeto Fome Zero, que compreendem os Bancos de Alimentos, os Restaurantes Populares e o PAA, foram associados, além de contribuir com o DHAA, a uma redução da pobreza em termos relativos no Brasil, e todos os condicionantes dessa situação[ ${ }^{[8]}$ realçando a 
importância de estudos que fiscalizam e analisam os impactos de políticas públicas na população.

Dessa forma, com o intuito de entender os fatores que condicionaram a adesão e descontinuidade ao programa, buscou-se caracterizar o perfil dos participantes. Para serem considerados aptos a receberem as "Cestas Verdes", os centros comunitários possuíam condicionantes de vulnerabilidade socioeconômica.

Ao serem questionados sobre a importância das cestas para eles e suas familias, os beneficiários afirmaram que essas contribuíam com gêneros alimentícios in natura, como frutas, hortaliças, raízes e tubérculos. A mandioca e a abobrinha, recebidas durante grande parte do programa, eram muito apreciadas pelos beneficiários, que compartilharam seus métodos de preparação, sendo o cozimento e fritura os mais empregados para a mandioca, e o refogado para a abobrinha. Esses dois alimentos também foram citados como presentes nas refeições de beneficiários do PAA em outros municípios, como Cerro Azul, Imbau e Querência do Norte, PR [24].

Em geral, todos os alimentos recebidos tiveram grande aceitação pelos beneficiários que expressaram satisfação com a diversidade das cestas. Os gêneros alimentícios eram conhecidos, o que foi comprovado pelos comentários livres durante as entrevistas sobre receitas preparadas que, muitas vezes, remetiam a preparações de família. Ademais, $97 \%$ dos beneficiários concordaram que os produtos recebidos contribuíam para a variedade de alimentos do domicílio e tornavam a alimentação da família mais saudável, indicando um impacto positivo do programa "Cestas Verdes" nos hábitos alimentares das famílias. Em outros municípios em que o PAA foi instituído, como em Campina do Monte Alegre, SP, o programa contribuiu com a redução de gastos com a alimentação e com a melhora do aspecto nutricional de seus beneficiários ${ }^{[25]}$.

Em relação à descontinuidade, buscou-se compreender os motivos que levaram $64,7 \%$ dos beneficiários a não receberem as cestas durante os dois anos de vigência do programa. Quando o programa "Cestas Verdes" foi institucionalizado em Limeira, SP, em 2015, ele atendia um grupo específico, que eram os coletores de recicláveis. Em 2016, os critérios de seleção sofreram modificação e passaram a atender outros estratos da população que também se encontravam em risco social. Dessa forma, a maioria dos beneficiários não recebeu a cesta durante todo o período em que o programa ficou em vigor por serem admitidos quando esse já estava em funcionamento. Independente do motivo da descontinuidade, quando um beneficiário era desvinculado do programa, outro cadastro era efetuado em substituição.

Como mostra o Quadro 1, outros fatores que contribuíram para que a porcentagem de descontinuidade tenha sido alta. Podem ser citados motivos de âmbito individual e/ou da política pública, o que inclui estar na lista de espera de recebimento, vieses de seleção dos beneficiários (em que famílias não eram aceitas nos critérios de seleção, porém se encontravam em situação de IAN e, por necessitarem dos alimentos, recebiam as cestas que não eram retiradas), horário e dia de distribuição da cesta inflexíveis, condições de saúde que impediam ou dificultavam a retirada da cesta, mudança de moradia, e dificuldade de locomoção. Cada fator de descontinuidade, independente da frequência com que apareceu, foi considerado com mesma importância devido à intenção do estudo de conceder notabilidade a todos os dificultantes de recebimento das cestas.

A dificuldade de transporte como uma barreira no consumo de frutas e hortaliça também foi observada por Figueira, Lopes \& Modena[26] em uma outra estratégia de promoção de alimentação saudável, o Programa Academia de Saúde (PAS), além de outros fatores como o alto custo dos produtos. Porém, esse aspecto foi amenizado pelo PAA por ter um caráter de distribuição gratuita de alimentos. 
Quadro 1. Fatores de descontinuidade dos beneficiários ao programa “Cestas Verdes”. 2017, Limeira, SP

\begin{tabular}{|c|c|}
\hline Âmbito Individual & $\begin{array}{l}\text { Compromisso no dia de retirada da cesta } \\
\text { Condições de saúde (mal-estar, depressão, dificuldade de locomoção) } \\
\text { Mudança de moradia para outro bairro } \\
\text { Insatisfação com os produtos recebidos } \\
\text { Cancelamento do cadastro no programa por possuir horta em casa } \\
\text { Esquecimento de buscar a cesta } \\
\text { Não sabe explicar o motivo de não retirar a cesta todas as vezes }\end{array}$ \\
\hline Âmbito da Política Pública & $\begin{array}{l}\text { Cadastro quando o programa já havia começado } \\
\text { Encontrava-se na lista de espera do programa } \\
\text { Viés de seleção do beneficiário, como descadastro - famílias não aceitas nos } \\
\text { critérios de seleção, mas que se encontravam em situação de IAN e, por } \\
\text { necessitarem dos alimentos, recebiam as cestas que não eram retiradas }\end{array}$ \\
\hline Misto - Âmbito Individual e da Política & $\begin{array}{l}\text { Horário e dia de distribuição da cesta } \\
\text { Problemas de comunicação entre CRAS e participantes } \\
\text { Cancelamento do cadastro no programa por algum motivo pessoal que não } \\
\text { mudava o quadro de IAN }\end{array}$ \\
\hline
\end{tabular}

Fonte: Elaboração das autoras. Limeira, SP. 2017.

Como apontado anteriormente, as entrevistas foram realizadas quando o programa "Cestas Verdes" não estava mais vigente, dessa forma, os beneficiários compartilharam suas experiências vivenciadas nos dois anos anteriores. A parte do questionário relativa à frequência de consumo alimentar refere-se aos hábitos alimentares no momento das entrevistas, sendo assim, não foram relatadas as contribuições de gêneros alimentícios oferecidas pela cesta.

Consequentemente, após o cancelamento do programa "Cestas Verdes", as frutas, verduras e legumes, grupos alimentícios considerados marcadores de alimentação saudável, se destacaram por terem seu consumo muito baixo entre os beneficiários. Como ilustrado nas figuras 1 a 3, 62,6\% dos beneficiários respondeu a opção "nunca" ou "quase nunca" ao serem questionados quantas vezes por semana consumiam frutas. Apenas $6 \%$ dos beneficiários relatou consumo regular desse grupo alimentício. Situação semelhante foi observada para verduras e legumes, em que 44,8\% e 55,2\% dos beneficiários, relatou baixo consumo desses grupos alimentícios, respectivamente.
Figura 1. Frequência de consumo de frutas pelos beneficiários do programa "Cestas Verdes". 2017, Limeira, SP

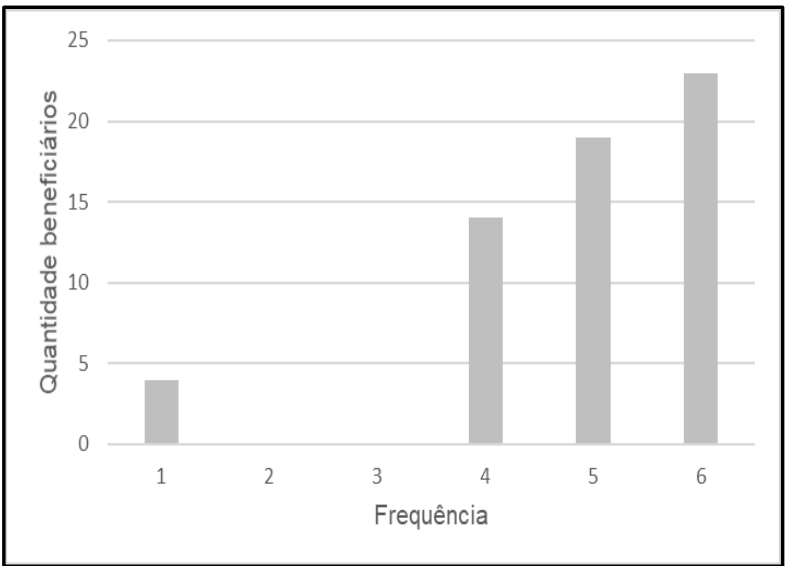

Obs.: Considerando-se frequência: 1) Todos os dias; 2) 5 a 6 vezes/semana; 3) 3 a 4 vezes/semana; 4) 1 a duas vezes/semana; 5) Quase nunca; 6) Nunca

Fonte: Elaboração das autoras. Limeira, SP. 2017. 
Figura 2. Frequência de consumo de verduras pelos beneficiários do programa "Cestas Verdes". 2017, Limeira, SP

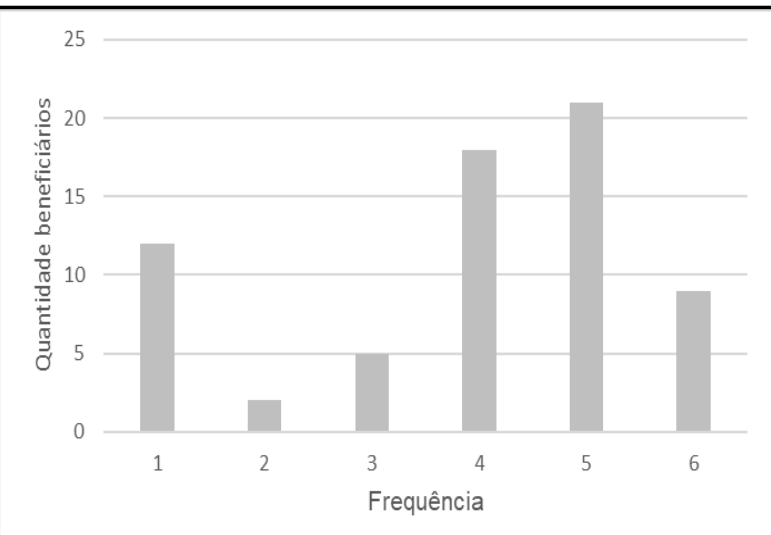

Obs.: Considerando-se frequência: 1) Todos os dias; 2) 5 a 6 vezes/semana; 3) 3 a 4 vezes/semana; 4) 1 a duas vezes/semana; 5) Quase nunca; 6) Nunca

Fonte: Elaboração das autoras. Limeira, SP. 2017.

Figura 3. Frequência de consumo de legumes pelos beneficiários do programa “Cestas Verdes", Limeira, SP

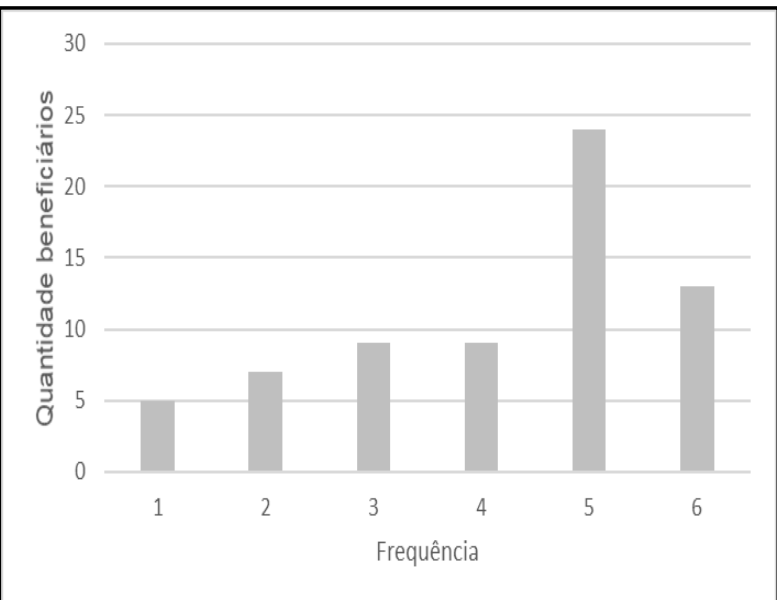

Obs.: Considerando-se frequência: 1) Todos os dias; 2) 5 a 6 vezes/semana; 3) 3 a 4 vezes/semana; 4) 1 a duas vezes/semana; 5) Quase nunca; 6) Nunca

Fonte: Elaboração das autoras. Limeira, SP. 2017.

Em relação aos outros alimentos, os que se destacaram pelo seu alto consumo foram o arroz e o feijão. O consumo diário de arroz foi relatado por $97 \%$ dos beneficiários, e o feijão por $82 \%$. Segundo estudo realizado por Barbosa (2007) no Brasil, 94\% dos integrantes da amostra declarou o hábito de consumir arroz e feijão no almoço[ ${ }^{[27]}$. Esses alimentos também se mostraram muito valorizados em estudo conduzido por Carneiro ${ }^{[22]}$ entre famílias beneficiárias do $\mathrm{PBF}$, que prezavam o consumo de mantimentos associados ao sustento.

Quando questionados sobre o desejo de mudar a alimentação do domicílio caso pudessem, $71,6 \%$ dos beneficiários responderam que sim. As respostas mais prevalentes sobre o que mudariam foram em relação à vontade de ter regularmente frutas e hortaliças $(58,2 \%)$ e carne $(14,9 \%)$ na rotina alimentar do domicílio.

Por fim, um outro resultado que se destacou foi a porcentagem de beneficiários em situação de IAN. Somente 5,9\% dos domicílios das famílias beneficiadas foram classificados em SAN. Assim, $94,1 \%$ encontrava-se em algum grau de IAN, sendo $29,9 \%$ em situação de IAN leve, 34,3\% em IAN moderada e $29,9 \%$ em IAN grave. A literatura mostra que domićlios de famílias vulneráveis apresentam maiores prevalências de IAN moderada ou grave. Essa relação se estende para domicílios chefiados por mulheres, e na presença de seis ou mais membros na família ${ }^{[28,29]}$.

Esses dados mostram a importância da existência de uma estratégia que colabore com o acesso de indivíduos em IAN a alimentos saudáveis, e, ainda, da manutenção dos beneficiários no programa, uma vez que esse se mostrou como uma possibilidade de acesso a frutas e hortaliças.

Estudos anteriores foram unânimes em relação aos efeitos positivos do PAA aos produtores, que lhes apresentou novas perspectivas de trabalho, aumentou a renda familiar, assegurou diversidade alimentar para o mercado e para o autoconsumo, impactando de forma positiva na situação de SAN de seus domicílios ${ }^{[30,31]}$. Ademais, segundo Souza e MarínLeón (2013), os idosos, que eram a maioria entre os beneficiários em IAN do programa "Cestas Verdes", apresentam maior risco de desenvolvimento de doenças crônicas, condições de saúde relatadas por grande parte dos beneficiários ${ }^{[32] .}$

Então, enquanto os beneficiários do programa "Cestas Verdes" constituem um grupo de vulnerabilidade econômica - critério decisivo para o cadastro -, grande parte encontrava-se em IAN, 
apresentava baixo consumo de frutas, legumes e verduras em momento no qual não recebiam as cestas. Panigassi et al. (2008) descrevem resultados semelhantes, como o consumo de frutas e hortaliças reduzido em domicílios em IAN, o que contribui para uma dieta monótona constituída por produtos de alta densidade energética[33]. Isso é reforçado por Rose (1999), ao apontar que, comumente, a IAN se correlata com dietas de baixa qualidade[34].

Ao serem questionados sobre possíveis mudanças que poderiam gerar melhorias ao programa, os beneficiários sugeriram a flexibilidade no dia e horário de entrega que eram considerados restritos, o desejo de receber mais tipos de frutas e melhoria das condições de transporte dos produtos que, algumas vezes, chegavam deteriorados. Pesquisas vem demonstrando que os parâmetros visuais têm se destacado na hora da escolha de frutas e hortaliças, revelando a importância de estratégias que minimizem os danos aos alimentos durante todo o processo póscolheita, incluindo no transporte[35].

Porém, apesar das limitações, evidenciou-se neste estudo o desejo e necessidade dos beneficiários ao acesso a alimentos saudáveis, como as frutas, hortaliças, raízes e tubérculos para o estímulo e a permanência de hábitos alimentares saudáveis. As "Cestas Verdes" foram descritas pelos beneficiários do programa como única fonte desses grupos de alimentos na dieta das famílias, uma vez que as prioridades de compra, como mostrado em outros estudos, geralmente se limitam a alimentos como arroz, feijão, farinha e macarrão, vistos como alimentos que geram sustento, e que é complementada com outros gêneros alimentícios conforme possibilidade financeira[22].

Constatou-se que, apesar dos fatores que condicionaram parte dos beneficiários a descontinuarem, o programa "Cestas Verdes" foi importante para garantir o acesso de famílias em situação de vulnerabilidade social e IAN a alimentos saudáveis, reforçando a necessidade de políticas públicas para garantia do DHAA.

\section{CONCLUSÃO}

Ao promover o acesso de populações em risco social e caracterizadas como em situação de IAN a alimentos de qualidade, o programa "Cestas Verdes", vertente ao PAA em Limeira, SP, expressou-se como uma ferramenta substancial na promoção do DHAA. Os beneficiários avaliaram que, quando recebiam as "Cestas Verdes", acessavam maior variedade de alimentos, o que tornava a alimentação da família mais saudável.

Em relação à observada descontinuidade ao programa por parte dos beneficiários, essa pode ser explicada por fatores relacionados tanto a suas condições de vida, como doenças ou agravos de saúde, dificuldade de locomoção, compromissos no dia de retirada da cesta, insatisfação com os produtos, dentre outros, quanto às características da gestão da política pública, que incluem, fundamentalmente, vieses de seleção, em que indivíduos pertencentes à domicílios que vivenciavam situação de IAN eram, muitas vezes, classificados como fila de espera para o recebimento da cesta.

Uma política pública isoladamente não é capaz de assegurar condições dignas de sobrevivência, sendo necessário um trabalho intersetorial que envolva as diversas políticas sociais, como de educação, produção, emprego, saúde e cultura. Contudo, o PAA e, no caso estudado, o programa "Cestas Verdes", de Limeira, SP, mostrou-se uma importante estratégia na garantia do DHAA.

\section{AGRADECIMENTOS} financeiro.

Agradecimentos ao $\mathrm{CNPq}$ pelo auxílio

\section{REFERÊNCIAS}

[1] UNICEF. Declaração Universal dos Direitos Humanos [Internet] 2018 [Acesso em 5 fev 2018]. Disponível em: https://www.unicef.org/brazil/pt/resources_10133.html

[2] Scolari DDG. Produção agrícola mundial: o potencial do Brasil. Embrapa[Internet] 2006. [Acesso em 5 fev 2018]. Disponível em: https://www.embrapa.br/busca-de-publicacoes/-

/publicacao/417182/producao-agricola-mundial-o-potencial-dobrasil

[3] Belik W, Capacle Correa VH. A Crise dos Alimentos e os Agravantes para a Fome Mundial [Internet] 2013 [Acesso em 6 fev 2018]. Disponível em: http://www.memoria.fahce.unlp.edu.ar/art_revistas/pr.5945/pr.59 45.pdf 
[4] Instituto Brasileiro de Geografia e Estatística - IBGE. Pesquisa Suplementar de Segurança Alimentar PNAD 2013 [Internet]. 2014 [Acesso em 6 fev 2018]. Disponível em: https://biblioteca.ibge.gov.br/visualizacao/livros/liv91984.pdf

[5] Castro J. Geografia da Fome. 5 ed. São Paulo: Editora Brasiliense; 1957.

[6] Kepple AW, Segall-Corrêa AM. Conceituando e medindo segurança alimentar e nutricional. Ciência \& Saúde Coletiva. 2011;16:187-199.

[7] Instituto Brasileiro de Geografia e Estatística - IBGE. Pesquisa Nacional por Amostra de Domicílios - 2015 [Internet] 2015 [Acesso em 5 fev 2018]. Disponível em: https://biblioteca.ibge.gov.br/visualizacao/livros/liv98887.pdf

[8] Belik W. A política brasileira de segurança alimentar e nutricional: concepção e resultados. Segur. Aliment. Nutr. 2012;9(2):94-110.

[9] Chmielewska D. The food security policy context in Brazil. In: Souza D.Country Study. Brasília: International Policy Centre for Inclusive Growth; 2011.

[10] Burlandy L. A construção da política de segurança alimentar e nutricional no Brasil: estratégias e desafios para a promoção da intersetorialidade no âmbito federal de governo. Ciência \& Saúde Coletiva. 2009;14:851-860.

[11] Brasil. Ministério do Desenvolvimento Agrário (MDA). Programa de Aquisição de Alimentos (PAA) [Internet] 2018 [Acesso em 7 mar 2018]. Disponível em: http://www.mda.gov.br/sitemda/secretaria/saf-paa/sobre-oprograma

[12] Fornazier A, Belik W. Produção e consumo local de alimentos: novas abordagens e perspectivas para as políticas públicas. Segur. Aliment. Nutr. 2013;20(2):204-218.

[13] Ribeiro CDSG, Moro FC, Auler F, Barbosa JF, Silveira JD, Corradi-Perini C. A Bioética no cenário da produção de alimentos: uma busca pela garantia do direito humano à alimentação adequada de escolares com necessidades alimentares especiais. Segur. Aliment. Nutr. 2015;22(1):662-670.

[14] Souza EBD. Transição nutricional no Brasil: análise dos principais fatores [Internet] 2010 [Acesso em 7 mar 2018]. Disponível http://web.unifoa.edu.br/cadernos/edicao/13/49.pdf.

[15] Instituto Brasileiro de Geografia e Estatística - IBGE. Estatísticas por Cidade e Estado - Limeira[Internet] 2018 [Acesso em 7 mar 2018]. Disponível em: https://cidades.ibge.gov.br/brasil/sp/limeira

[16] Instituto Brasileiro de Geografia e Estatística - IBGE. Mapa de Pobreza e Desigualdade - Limeira [Internet] 2018 [Acesso em 10 mar 2018]. Disponível em:

https://cidades.ibge.gov.br/brasil/sp/pesquisa/36/30249

[17] CEPROSOM. Diretoria de Proteção Social [Internet] 2018 [Acesso em 10 mar 2018]. Disponível em: http://www.ceprosom.sp.gov.br/portal2/psb

[18] Agência de Notícias São Luís. Prefeitura entrega cestas do Programa de Aquisição de Alimentos a famílias do Bequimão e adjacências [Internet] 2017 [Acesso em 10 mar 2018]. Disponível em: http://www.agenciasaoluis.com.br/noticia/18636

[19] Sindicato dos Metalúrgicos de Sorocaba e Região. Banco de Alimentos dá início ao programa Cesta Verde [Internet]. 2015 [Acesso em 10 mar 2018]. Disponível em: https://www.smetal.org.br/noticias/banco-de-alimentos-da-inicioao-programa-cesta-verde/20150520-122241-a980

[20] Frizo BLS, Grilo MF, Oliveira JM. Programa "Cestas Verdes": análise sociotécnica de uma política que conecta produção e consumo na cidade de Limeira, SP. 2019. In prole.

[21] Gonçalves MP, Campos ST, Sarti FM. Políticas públicas de segurança alimentar no Brasil: uma análise do Programa de Restaurantes Populares. Revista Gestão \& Políticas Públicas. 2011;1(1).

[22] Carneiro DF. Práticas alimentares e estratégias de enfrentamento da insegurança alimentar e nutricional de famílias em vulnerabilidade social [Internet] 2015 [Acesso em 9 mar 2018]. Disponível em: https://acervodigital.ufpr.br/handle/1884/41862

[23] Ferreira VA, Magalhães R. Práticas alimentares de mulheres beneficiárias do Programa Bolsa Família na perspectiva da promoção da saúde. Saúde e Sociedade. 2017;26:987-998.

[24] Doretto M, Michellon E. Avaliação dos Impactos Econômicos, Sociais e Culturais do Programa de Aquisição de Alimentos no Paraná [Internet] 2007 [Acesso em 9 mar 2018]. Disponível em: http://www.iapar.br/arquivos/File/zip_pdf/aval_impact_econo.p df

[25] Agapto JP, Borsatto RS, Esquerdo VFDS, Bergamasco SMPP. Avaliação do Programa de Aquisição de Alimentos (PAA) em Campina do Monte Alegre, estado de São Paulo, a partir da percepção dos agricultores [Internet] 2012 [Acesso em 13 mar 2018]. Disponível em: http://www.iea.sp.gov.br/ftpiea/publicacoes/IE/2012/tec2-0304-2012.pdf

[26] Figueira TR, Lopes ACS, Modena CM. Barreiras e fatores promotores do consumo de frutas e hortaliças entre usuários do Programa Academia da Saúde. Rev. Nutr. 2016;29:85-95.

[27] Barbosa L. Feijão com arroz e arroz com feijão: o Brasil no prato dos brasileiros. Horizontes Antropológicos. 2007;13:87-116. 
[28] Marin-Leon L, Francisco PMSB, Segall-Corrêa AM, Panigassi G. Bens de consumo e insegurança alimentar: diferenças de gênero, cor de pele autorreferida e condição socioeconômica [Internet] 2011 [Acesso em 10 mar 2018]. Disponível em: http://www.scielo.br/scielo.php?script=sci_arttext\&pid=S1415790X2011000300005\&lng=en

[29] Segall-Corrêa AM, Marin-Leon L, Helito H, Pérez-Escamilla R, Santos LMP, Paes-Sousa R. Transferência de renda e segurança alimentar no Brasil: análise dos dados nacionais. Rev. Nutr. 2008;21:39s-51s.

[30] Assis SCRD, Priore SE, Franceschini SDCC. Impacto do Programa de Aquisição de Alimentos na Segurança Alimentar e Nutricional dos agricultores. Ciência \& Saúde Coletiva. 2017;22:617-626.

[31] Hespanhol RADM. Programa de Aquisição de Alimentos: limites e potencialidades de políticas de segurança alimentar para a agricultura familiar. Sociedade \& Natureza. 2013;25:469-483.

[32] Souza BFDNJD, Marín-León L. Food insecurity among the elderly: cross-sectional study with soup kitchen users. Rev. Nutr. 2013;26:679-691.

[33] Panigassi G, Segall-Corrêa AM, Marin-León L, Pérez-Escamilla R, Maranha LK, Sampaio MDFA. Insegurança alimentar intrafamiliar e perfil de consumo de alimentos. Rev. Nutr. 2008;21:135-144.

[34] Rose D. Economic determinants and dietary consequences of food insecurity in the United States. J Nutr. 1999; 129(2l):517-520.

[35] Figueira TR, Lopes ACS, Modena CM. Avaliação do consumo de frutas e hortaliças entre famílias de usuários do Programa Academia da Saúde (PAS) [Internet] 2014 [Acesso em 13 mar 2018]. Disponível https://periodicos.unifor.br/RBPS/article/view/2852 